\title{
Scale Accretion on Homogenization Furnace Rollers in Compact Strip Production Mills and Its Densification Mechanism
}

\author{
Yuan-zhi ZHU, ${ }^{1,2)}$ Xiao-jun CHENG, ${ }^{3)}$ Z. D. XIANG ${ }^{21}$ and Zhe ZHU ${ }^{1)}$ \\ 1) Key Laboratory for Ferrous Metallurgy and Resources Utilization of Ministry of Education, Wuhan University of Science and \\ Technology, Wuhan 430081, China. $\quad$ 2) School of Materials and Metallurgy, Wuhan University of Science \& Technology, \\ Wuhan 430081, China. $\quad 3$ 3) Lianyuan Iron and Steel LTD Co., Loudi 417000, China.
}

(Received on November 9, 2007; accepted on February 8, 2008)

\begin{abstract}
SEM, EDS, XRD, ICP-AES and DTA were used to analyze the densification mechanism of the scale accretion on homogenization furnace rollers in compact strip production line. It was discovered that the accumulated scale was composed of many layers. A thin outer layer was relatively loose and thick inner layers were hard and densified. There were great differences in phase types between the loose and the densified layers. The loose layer was composed of mainly $\mathrm{Fe}_{2} \mathrm{O}_{3}$ with minor $\mathrm{Fe}_{3} \mathrm{O}_{4}$. However, the densified layers consisted of $\mathrm{FeO}$ and $\mathrm{Fe}_{3} \mathrm{O}_{4}$; $\mathrm{FeO}$ was formed on billets at high temperatures, which was transformed to $\mathrm{Fe}_{3} \mathrm{O}_{4}$ at low oxygen partial pressure. Owing to the weight of the billet, the picked-up scale became densified. A great amount of wustite $\mathrm{Fe}_{(1-x)} \mathrm{O}$ in a shape of star was discovered distributing dispersedly in the scale accretion, resulting in a higher strength of it. Additionally, the minor residual elements of low melting point, such as Mg, As, Cu from billet and sulfur from burning gas were melted, resulting in an acceleration of the densification process. On the contrary, the outer surface layer of the scale accretion was partly changed to $\mathrm{Fe}_{2} \mathrm{O}_{3}$ by the oxygen in the furnace in blow-off process, leading to a loose-layer.

KEY WORDS: Compact strip production; furnace roller; scale accretion; densification mechanism.
\end{abstract}

\section{Introduction}

Compact strip production (CSP) is a novel technology developed in 1980s for casting-hot-rolling of thin slabs. It is new technological innovation following converter steelmaking and continuous casting technology in steel industry. This technology provides a more compact line and a more simple procedure as compared with the traditional hot rolling technology. However, surface defects, such as inclusions, cracks and rolled-in scale may be a problem concerning with CSP products if the technique parameters are not controlled properly. ${ }^{1-5)}$ Rolled-in scale may result from two type's origins. One is the rolled-in oxide scale which is not descaled completely by high pressure water. The other origin is the scale picked-up on rollers in the homogenization furnace, which is rolled into the billet in the following rolling pass. The factors that influence the descaling process were reported by some other researchers. ${ }^{6-8)}$ Scale accretion on rollers in the homogenization furnace frequently occurs in CSP lines in steel factories. Li reported the influence of furnace atmosphere on scale accretion on rollers in a homogenization furnace, but he did not explain the influence of the concrete chemical composition in the furnace atmosphere. ${ }^{9)}$ Wang investigated the resistance to scale accretion of different coatings on rollers. ${ }^{10)}$ Li Donghui studied the influence of the oxygen pressure on scale accretion on furnace rollers. ${ }^{11)}$ Tiley John reported the compressive properties of the scale at temperatures below $650^{\circ} \mathrm{C} .{ }^{12)}$ Actually, there are many factors, such as phases, residual chemical composition from furnace atmosphere and steel billets leading to scale accretion on furnace rollers. However, few reports are available on the physical and chemical mechanism by considering all these factors. This paper aims at investigating the influences of oxide scale phases and residual chemical compositions from furnace atmosphere and steel billets on the formation of scale accretion on furnace rollers.

\section{Experiment}

It was found that scale accretion on furnace homogenization rollers is a common phenomenon on CSP line in many steel factories. Figure 1 shows a typical scale accretion collected from a furnace roller of a CSP line in a factory. This scale accretion was obtained from a furnace roller once the

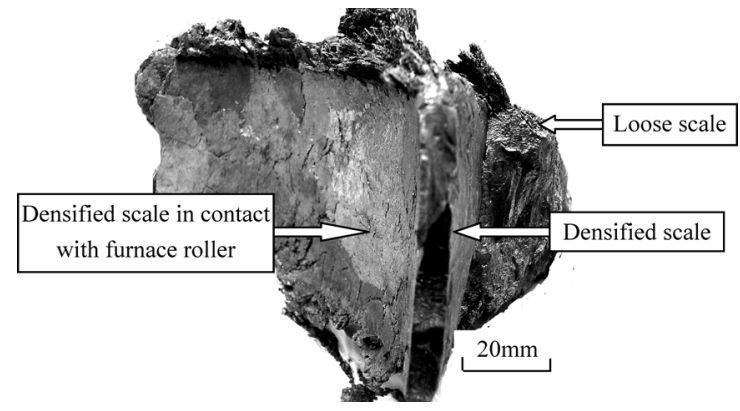

Fig. 1. Typical photograph of the accretion scale on a furnace roller. 


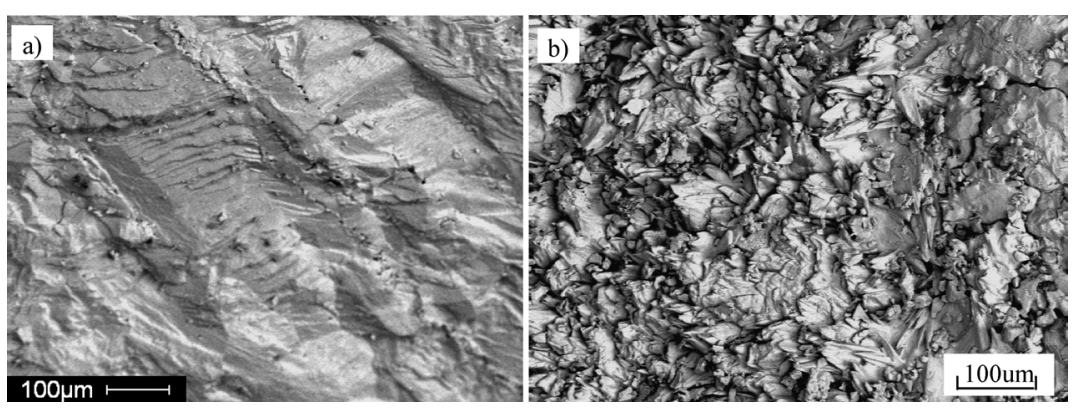

Fig. 2. Micrograph of the surface of the scale accretion, (a) densified scale and (b) loose scale.

amount of the processed steel passed over the roller in the CSP line exceeded 10000 tons. It shows that the scale accretion includes two layers. Its outer layer that did not contact with furnace rollers directly is loose. Its thickness is about $20 \mathrm{~mm}$. The other layer with a thickness of about $60 \mathrm{~mm}$ contacting with the furnace roller is densified.

Chemical compositions of the both layers were investigated using ICP-AES. SEM and EDS analysis were performed for the both layers of the scale accretion using a Siron 2000 scanning electron microscope attached with an EDS system.

Samples were collected from both of the two layers. They were ball milled into powders with a size of -200 meshes. The powders were used for XRD analysis with a D/MAX2550VB+ system manufactured by RIGAKA Company at an acceleration voltage of $36 \mathrm{kV}$, a current of $28 \mathrm{~mA}$, a scanning rate of $2 \% \mathrm{~min}$ and $\mathrm{CuK} \alpha$ as radiation.

Microstructures of the densified layer were also investigated by OM and SEM. Firstly, the densified scale layer was made into OM samples following the standard procedure. Then the samples were etched with $2 \%$ nital solution. $\mathrm{OM}$ analysis was done on a Polymeter produced in Germany.

\section{Results and Discussions}

\subsection{Chemical Compositions}

Chemical composition of the scale accretion is shown in Table 1. It shows that minor $\mathrm{Mg}, \mathrm{Al}, \mathrm{S}$ and $\mathrm{Cu}$ are present in both of the two layers. It seems that the concentration of the minor elements in the densified layer is slightly higher than that in the loose one.

\subsection{SEM and XRD Analysis of the Surface of the Scale Accretion}

The SEM images of the surface of the both two layers are given in Fig. 2. It shows that the surface of the densified layer is very compact without any major defects. In contrast, micro-cracks and a great number of needle-like phases can be observed on the surface of the loose layer.

XRD was used for analysing both the loose and densified layers. The results are given in Fig. 3. The results show that the loose layer contains mostly $\mathrm{Fe}_{2} \mathrm{O}_{3}$ with a minor amount of $\mathrm{Fe}_{3} \mathrm{O}_{4}$. The major phases in the densified layer are $\mathrm{FeO}$ and $\mathrm{Fe}_{3} \mathrm{O}_{4}$. The amount of $\mathrm{Fe}_{3} \mathrm{O}_{4}$ in the densified layer is much larger than that in the loose one. Additionally, a trace amount of Fe was detected in the densified layer. This iron may come from the hot steel billet in the homogenization furnace. Iron was adhered to the furnace roller and was not
Table 1. The main metallic elements in the scale (mass \%).

\begin{tabular}{llllllll}
\hline element & $\mathrm{Cu}$ & $\mathrm{S}$ & $\mathrm{Al}$ & $\mathrm{Mg}$ & $\mathrm{Si}$ & $\mathrm{As}$ & $\mathrm{Fe}$ \\
\hline Densified layer & 0.016 & 0.12 & 0.06 & 0.03 & 0.05 & 0.05 & Bal. \\
Loose layer & 0.005 & 0.05 & 0.03 & 0.005 & 0.06 & 0.01 & Bal. \\
\hline
\end{tabular}

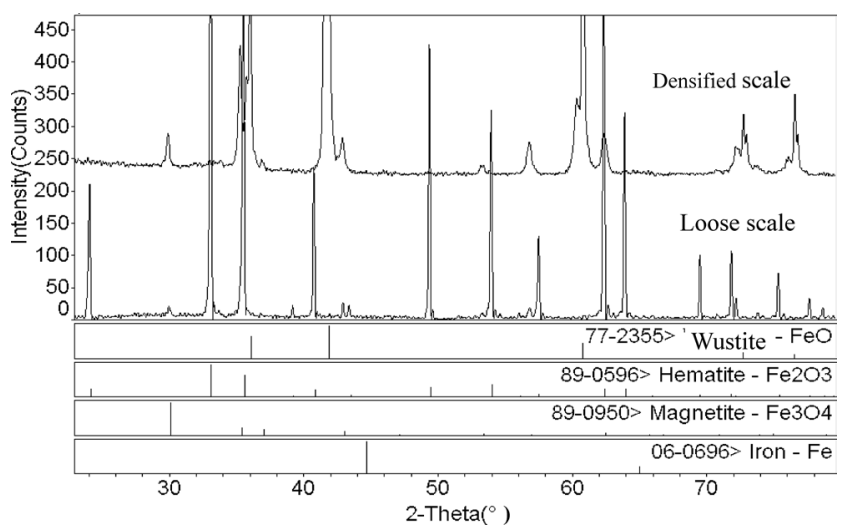

Fig. 3. Phases in the accretion scale.

oxidized in a deoxidized atmosphere in the furnace.

\subsection{Oxygen Content in the Two Layers}

EDS was done on both the loose and densified layers of the scale accretion. The results are given in Fig. 4. It shows that the oxygen content in the loose layer is higher than that in the densified layer. In the homogenization furnace, the temperature was higher than $1100^{\circ} \mathrm{C}$. FeO may be stable at such a high temperature in the air. ${ }^{13)}$ The major oxide of the scale accretion should be $\mathrm{FeO}$ at such a high temperature in the homogenization furnace. $\mathrm{Fe}_{2} \mathrm{O}_{3}$ may form in the process of the blowing-off of the furnace when the temperature in the furnace lowered to a certain value. $\mathrm{Fe}_{3} \mathrm{O}_{4}$ is a transitional oxide between $\mathrm{Fe}_{2} \mathrm{O}_{3}$ and $\mathrm{FeO}$. It is certain that the scale accretion comes from the scale on the surface of the billet at high temperature. Therefore, the major scale accretion should be $\mathrm{FeO}$.

The $\mathrm{FeO}$ and $\mathrm{Fe}_{3} \mathrm{O}_{4}$ formed at high temperatures are polygonal grains, but $\mathrm{Fe}_{2} \mathrm{O}_{3}$ is a needle-like phase. ${ }^{13)}$ The $\mathrm{FeO}$ grain is able to bear some plastic deformation. The $\mathrm{Fe}_{3} \mathrm{O}_{4}$ grain is small in size. The $\mathrm{Fe}_{3} \mathrm{O}_{4}$ is very compact. The mixed scale of $\mathrm{FeO}$ and $\mathrm{Fe}_{3} \mathrm{O}_{4}$ was compressed and sheared, because of both the weight of the billet on it and the friction between the scale and the moving billet. The porosities were welded and the scale accretion was densified by its plastic flow at high temperatures. After the densi- 

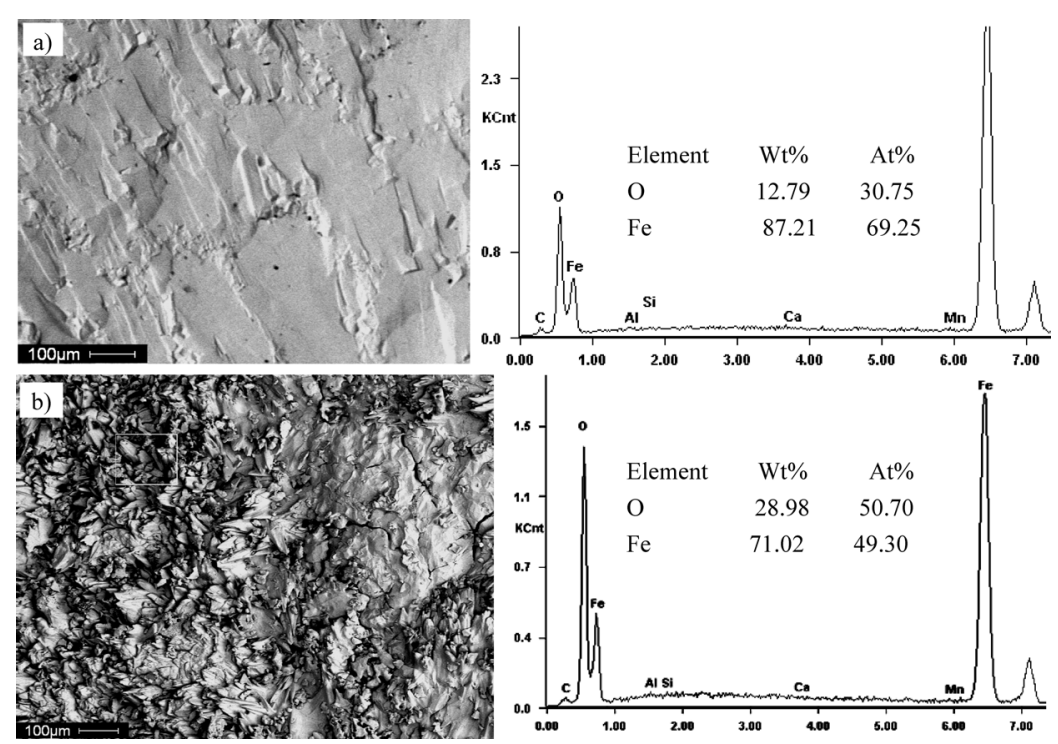

Fig. 4. SEM images and oxygen content in different scale layers, (a) densified layer and (b) loose layer.

fication, the oxygen in the furnace was stopped diffusing into the inner layer of the scale accretion through the closed pores. However, the outer layer of scale accretion was still in contact with oxygen in the furnace. The $\mathrm{FeO}$ and $\mathrm{Fe}_{3} \mathrm{O}_{4}$ in this layer may be turned into the needle-like $\mathrm{Fe}_{2} \mathrm{O}_{3}$ by the oxygen at a relatively low temperature during the blowingoff of the furnace. This kind of phase transformation would result in a volume change of the outer layer. Thus, residual stress may originate in the outer layer. Micro-cracks would appear. The whole outer layer became loose.

Temperature, oxygen pressure and atmosphere in the furnace may have great influences on the phase transformation. For example, a change of the chemical composition in the burning gas may result in a variation of the furnace temperature. The upward fluctuations of furnace temperature or a deoxidized atmosphere in the furnace usually causes severe adherence of steel onto furnace rollers.

\subsection{Microstructures of the Densified Layer}

Microstructures of the densified layer are illustrated in Fig. 5. It shows that irregular pores with a size of less than $20 \mu \mathrm{m}$ can be observed in the microstructure of the densified scale accretion. Plastic flowing can also be seen around some of the pores in Fig. 5(c), indicating that the scale has high plasticity at high temperature. In the matrix of $\mathrm{FeO}$, star-like oxides can be observed distributing dispersedly in some regions. This kind of oxide is only several microns in dimension with a higher oxygen content than that in the matrix, which may be $\mathrm{Fe}_{(1-x)} \mathrm{O}$. The parameter " $x$ " may depend on the oxygen partial pressure in the furnace. ${ }^{14)}$ If the matrix of the densified scale accretion tends to deform, starlike oxide may be a resistance to this deformation. The backscattered image and the EDS results show the presence of $\mathrm{Mg}, \mathrm{Al}$ and $\mathrm{Si}$ distributing uniformly in the matrix. The distribution of star-like $\mathrm{Fe}_{(1-x)} \mathrm{O}$ and these minor residual elements indicate a high strength of the densified scale accretion.

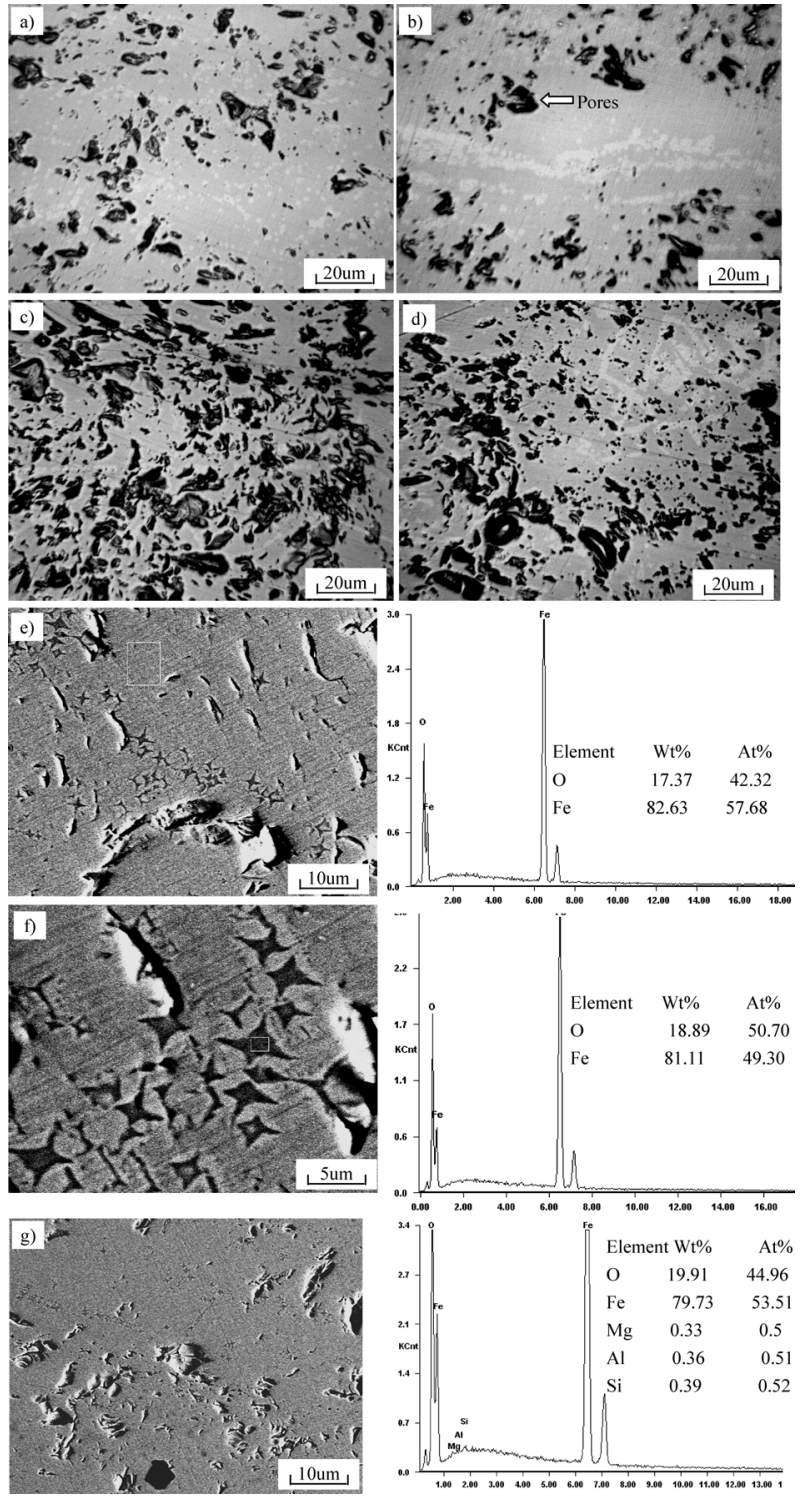

Fig. 5. Microstructures of the densified scale accretion. (a-d) Phase distribution in the densified scale, (e-f) micrograph of the star-like phase and $(\mathrm{g})$ minor chemical composition in the densified scale. 


\subsection{Effects of Minor Chemical Composition on the Densification of the Scale Accretion}

Many kinds of minor elements, such as $\mathrm{Cu}, \mathrm{S}, \mathrm{As}, \mathrm{Al}$ and $\mathrm{Mg}$ were present in the scale accretion. These elements and most of their compounds have a low melting point or boiling point. These minor elements may have a great influence on the densification of the scale accretion. Figure $\mathbf{6}$ is the DTA result of the densified scale.

It shows that there are obvious heat absorption peaks in the DTA result at 243, 359, 479, 727, 852, 973 and $1101^{\circ} \mathrm{C}$. The shape of the heat absorption peaks indicates that these peaks correspond to the melting of some substance in the densified scale. These substances may be compounds of the detected minor elements. The melting and boiling points of some compounds comprising the detected minor elements are shown in Table 2.

Among the heat absorption peaks, the peak at $479^{\circ} \mathrm{C}$ may be due to the boiling of sulfur or melting of its compounds. The height of the peak at $479^{\circ} \mathrm{C}$ is the highest among all the peaks, which may suggest that among all the minor elements with low melting points, the sulfur content is the largest. The two peaks at $243^{\circ} \mathrm{C}$ and $359^{\circ} \mathrm{C}$ may indicate the melting or evaporation of some sulfur compounds. The peak at $1101^{\circ} \mathrm{C}$ may correspond to the melting process of copper. Additionally, Silicon may react with $\mathrm{FeO}$ and produce $\mathrm{Fe}_{2} \mathrm{SiO}_{4}$, the melting point of which is lower than that of iron. $\mathrm{Fe}_{2} \mathrm{SiO}_{4}$ can also react with $\mathrm{FeO}$ and produce a kind of eutectic substance with a low melting point. The above considerations imply that there may be a liquid phase exist-

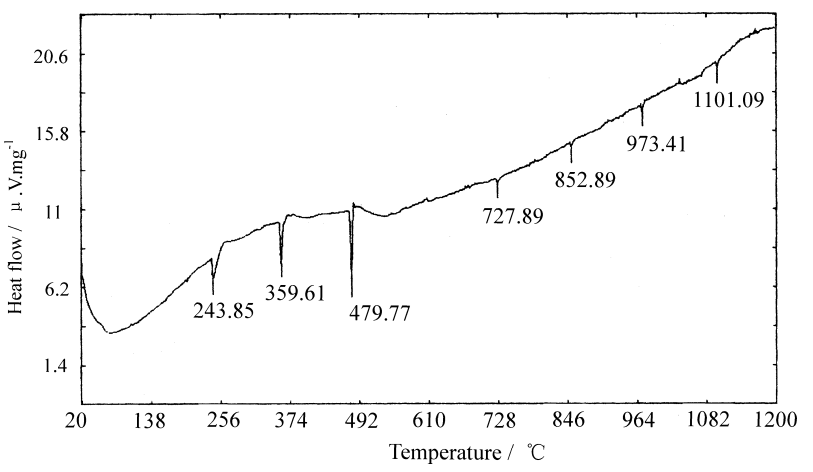

Fig. 6. DTA result of the densified scale layer. ing in the scale at high temperature, causing compressive liquid sintering of the scale accretion in the furnace. The scale accretion was further densified. ${ }^{15)}$

Among the minor elements detected, copper should come from the billet itself, because the CSP mill was previously used to roll copper containing steel, such as SPA-H. Arsenic is a typical residual element in steel, which has a tendency of concentrating to the surface of steel billet and then may be in turn transferred into the scale. It is noticeable that sulfur content was in the scale. It is impossible that the steel billet could contain a large quantity of sulfur. Sulfur may come from the burning gas. The burning gas used in the factories was blast furnace gas. This kind of burning gas may contain sulfur or $\mathrm{H}_{2} \mathrm{~S}$, which may deposit onto the surface of the scale or react with iron to form $\mathrm{FeS}$ at high temperatures.

\subsection{Mechanism of the Densification of the Scale Ac- cretion}

The densified scale accretion is composed of many layers. When a billet enters into the homogenization furnace, its bottom surface would be in contact with the furnace rollers. The scale on the bottom surface of the billet may be welded onto the surface of the furnace rollers under the weight of the billet. The scale $\mathrm{FeO}$ and the surface of furnace rollers may be "soft" at high temperatures, which make the scale more easily welded onto the rollers. Once one layer of the scale from billet is welded onto the rollers, the surface of the welded scale may be transformed into $\mathrm{Fe}_{3} \mathrm{O}_{4}$ at certain oxygen pressure, and thus the surface becomes more densified. After the heating process of one billet in the homogenization furnace is completed, a second billet would repeat the similar process as the former one, leading to scale accretion. The presence of residual elements accelerates the densification process of the scale accretion. The whole densification process can be illustrated by Fig. 7 .

\section{Conclusions}

There are big differences in phases between the loose layer and the densified layer of the scale accretion on furnace rollers of a CSP line. The loose layer is composed of mostly $\mathrm{Fe}_{2} \mathrm{O}_{3}$ with small amount of $\mathrm{Fe}_{3} \mathrm{O}_{4}$, while the densi-

Table 2. The melting and boiling points of the minor elements, and their compounds in the studied scale $/{ }^{\circ} \mathrm{C}$.

\begin{tabular}{lcccccccccr}
\hline & $\mathrm{Al}$ & $\alpha-\mathrm{As}$ & $\gamma-\mathrm{As}$ & $\mathrm{Cu}$ & $\mathrm{CuO}$ & $\mathrm{CuS}$ & $\mathrm{FeS}$ & $\mathrm{Mg}$ & $\mathrm{Fe}_{2} \mathrm{SiO}_{4}$ & $\mathrm{~S}$ \\
\hline $\begin{array}{l}\text { Melting } \\
\text { point }\end{array}$ & 660 & 814 & 358 & 1083 & 1026 & 103 & 1193 & 651 & 1173 & 120 \\
$\begin{array}{l}\text { Boiling } \\
\text { point }\end{array}$ & & & & & & & & & & \\
\hline
\end{tabular}

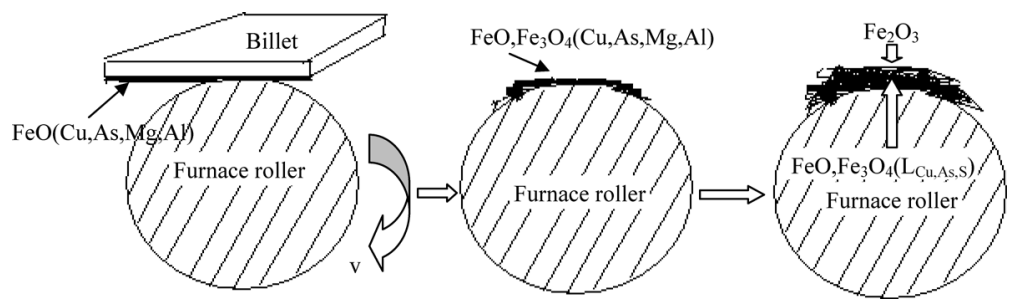

Fig. 7. Schematic illustration of the accretion and densification of the scale on furnace rollers. 
fied layer is composed of $\mathrm{FeO}$ and $\mathrm{Fe}_{3} \mathrm{O}_{4}$. The densified scale accretion was piled up with $\mathrm{FeO}$ layer by layer. Some $\mathrm{FeO}$ would be transformed into $\mathrm{Fe}_{3} \mathrm{O}_{4}$ at a low oxygen partial pressure. A great amount of star-like $\mathrm{Fe}_{(1-x)} \mathrm{O}$ grains was formed and randomly distributed in the densified scale layer, further strengthening the scale accretion. The residual minor elements, such as $\mathrm{Mg}, \mathrm{As}, \mathrm{Cu}, \mathrm{Al}$ and sulfur deposited from burning gas further densify the scale accretion.

\section{REFERENCES}

1) S. J. E. Camporredondo, E. A. H. Castillejos, G. F. A. Acosta, M. E. P. Gutierrez and G. M. A. Herrera: Metall. Mater. Trans. B, 35B (2004), 541.

2) E. Kerr, R. Webber and D. McCaw: Ironmaking Steelmaking, 31
(2004), 295.

3) H. Wolfgang, B. Christian and R. Carl-Peter: SEAISI Q., 34 (2005), 9.

4) G. H. Jiao, G. L. Wu, A. H. Sun, X. J. Cheng and C. Q. Zhou: Iron Steel, 41 (2006), 27.

5) P. G Xu, F. X. Yin and K. Nagai: Mater. Trans., 45 (2004), 2456.

6) Y. M. Che, T. Zhu, H. M. Zhang, M. Dong and Q. A. Chen: Iron Steel, 41 (2006), 63.

7) R. A. Adam: Iron Age New Steel, 13 (1997), 103

8) W. Sherwood and S. R. Shatynski: Surf. Technol., 21 (1984), 39.

9) Q. S. Li: Baosteel Technol., 3 (2004), 56.

10) L. Wang: Mater. Prot., 11 (2006), 68.

11) D. H. Li: Steel Rolling, 4 (2005), 57.

12) T. John, Y. M. Zhang and L. G. John: Steel Res., 70 (1999), 437.

13) B. K. Kim and S. Jerzy: JOM, 56 (2004), 154

14) D. Klimm and S. Ganschow: J. Cryst. Growth, 275 (2005), e849.

15) T. Fukagawa, H. Okada and Y. Maehara: ISIJ Int., 34 (1994), 906. 